NBSIR 86-3306

\title{
Procedure for Calibration of Ferrite Gaps in Magnetic Tape Heads Traceable to NBS AR-Chromium Optical Linewidth SRMs
}

\section{Aㅍㅁㄷ 5111}

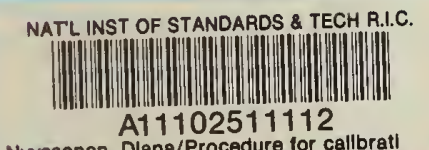

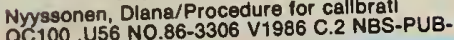

U.S. DEPARTMENT OF COMMERCE

National Bureau of Standards

National Engineering Laboratory

Center for Electronics and Electrical Engineering

Semiconductor Electronics Division

Gaithersburg, MD 20899

February 1986

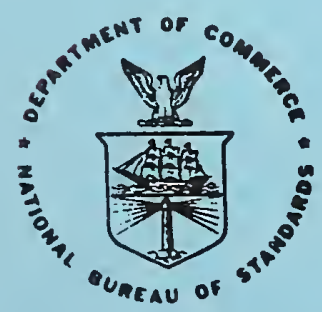

U.S. DEPARTMENT OF COMMERCE

$Q C$ aL BUREAU OF STANDARDS

100

.456

$86-3306$

1986

C. 2 

NBSIR 86-3306

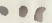

PROCEDURE FOR CALIBRATION OF FERRITE GAPS IN MAGNETIC TAPE HEADS TRACEABLE TO NBS AR-CHROMIUM OPTICAL LINEWIDTH SRMS

D. Nyyssonen

U.S. DEPARTMENT OF COMMERCE Nationa! Bureau of Standards

Center for Electronics and Electrical Engineering Semiconductor Electronics Division

Gaithersburg, MD 20899

February 1986

U.S. DEPARTMENT OF COMMERCE, Malcolm Baldrige, Secretary NATIONAL BUREAU OF STANDARDS, Ernest Ambler, Director 



\author{
Procedure for Calibration \\ of \\ Ferrite Gaps in Magnetic Tape Heads \\ Traceable to \\ NBS AR-Chromium Optical Linewidth SRMS \\ Diana Nyyssonen \\ Semiconductor Electronics Division \\ National Bureau of Standards \\ Gaithersburg, MD 20899
}

Abstract

Accurate calibration of micrometer and submicrometer optical linewidth measuring systems requires that the calibration standard match the properties of the line to be measured. The NBS photomask linewidth standards have been designed for use by the integrated circuit community and are not directly suitable for use in other applications. A method of calibrating systems for measuring the width of ferrite gaps in magnetic tape heads has been developed that involves a two-step calibration using the NBS antireflectingchromium photomask as the primary reference standard. This primary standard is used in transmitted green light to calibrate the linewidths on a secondary black-chromium photomask. This is a valid procedure because these lines are patterned in black-chromium layers that are thin compared to the wavelength of the green light and have negligible transmission. Since this secondary blackchromium photomask has similar optical properties to ferrite gaps when viewed in reflected green light, it can then be used to calibrate the linewidth measuring system to be used for ferrite gaps. The results of a preliminary study of this method shows that the errors associated with this two-step process are below $0.1 \mu \mathrm{m}$. The study also indicated that without this two-step process, the errors could be $0.3 \mu \mathrm{m}$ or more.

Key words: dimensional metrology; gapwidth; linewidth; NBS photomask standards; magnetic tape heads; tape-head gaps 
Accurate calibration and transfer of micrometer and submicrometer linewidth measurements optically using a standard reference material (SRM) required that the optical parameters of normalized transmittance (or reflectance) and phase at the line edge as shown in figure 1 for both the SRM and the part to be measured match. When they do match, the optical edge image profiles or waveforms used by the system to make the measurements will be the same, and accurate transfer of dimensions is possible.

Using the method to be described here, either the edge detection threshold used by the system is set to some value using the SRM, or when a fixed threshold or other edge detection criterion is used, the measurement data are corrected based on a calibration curve derived from the SRM measurement data. If the optical parameters do not match, the adjustment of the edge detection threshold or the correction applied to the data will be incorrect for the part being measured, and errors will result.

It is because of this source of error that the use of the NBS anti-reflective (AR) chromium optical linewidth SRM will result in measurement errors if used in any other mode than that for which it was intended, i.e., measurement of opaque photomask materials viewed in transmitted light at a mean wavelength of approximately $530 \mathrm{~nm}$.

However, for the case of measurement of the width of the ferrite gaps in magnetic tape heads, a two-step calibration method has been devised which appears to yield a reasonably accurate calibration and transfer of linewidth measurements. This method uses a secondary standard, a black-chromium photomask consisting of a single opaque chromium-oxide etched layer on a glass substrate which has the following properties: 1) it is opaque when viewed in transmission and therefore matches the transmission optical parameters of the NBS AR-chromium photomask SRMs, and 2) when viewed in reflection, its optical parameters are very close to the optical parameters of the ferrite gap in magnetic tape heads (fig. 2).

In this method, a transmitted light optical linewidth measurement system is set up and calibrated following the procedures accompanying the NBS AR- 


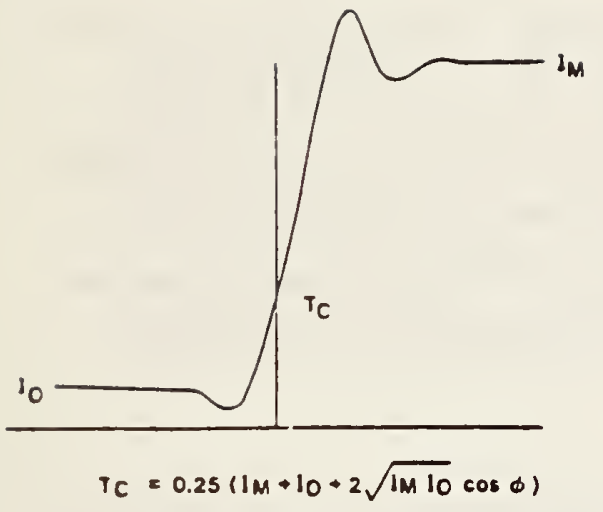

(a)

\section{TRAKSMITTED}

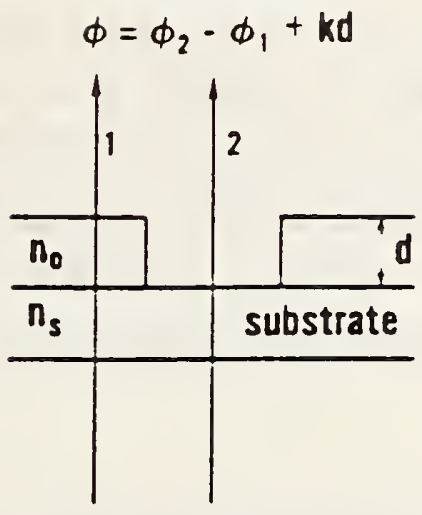

(b)

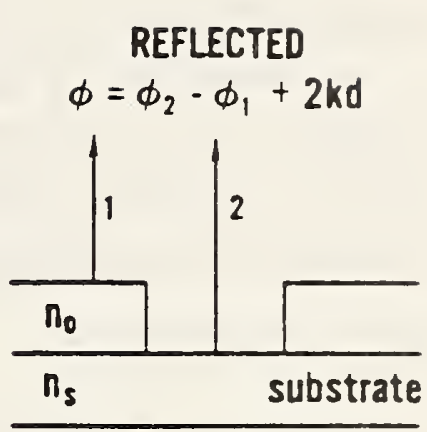

(c)

Figure 1. Definition of parameters $R$ and $\phi$ used to characterize line object. (a) Image edge profile showing $I_{M}$ and $I_{O}$ where $R=I_{O} / I_{M} \cdot T_{C}$ is the optical intensity threshold corresponding to the edge location. The optical phase difference $\phi$ is determined from the optical path difference between rays 1 and 2 for transmitted light (b) and reflected light (c). In each case, the values of $\phi_{1}$ and $\phi_{2}$ can be calculated from the given complex indices of refraction $n_{0}$ and $n_{s}$ and the thickness $d$ of the etched layer using the Fresnel equations. $\phi_{1}$ and $\phi_{2}$ represent the phase change of the respective rays upon reflection or transmission.

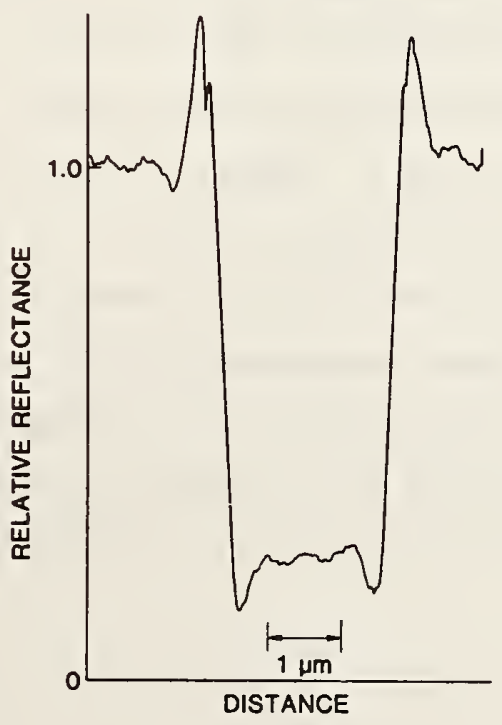

(a)

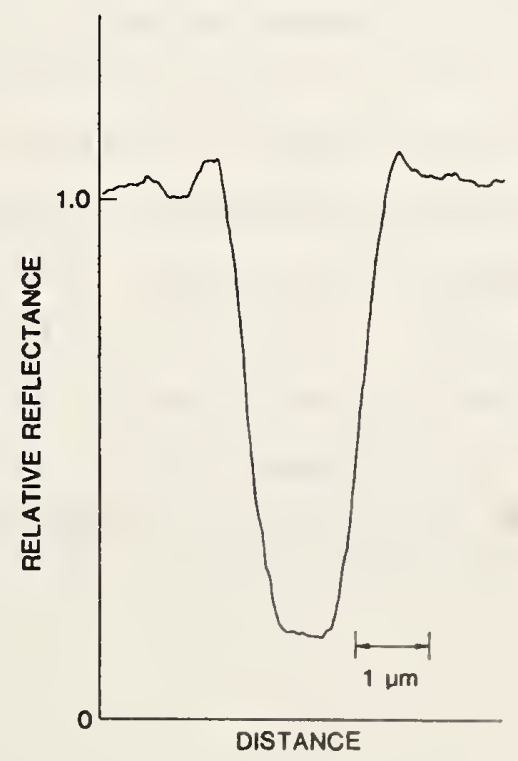

(b)

Figure 2. Comparison of the image profiles (waveforms) for reflected light measurement of (a) black-chromium photomask, and (b) the ferrite gap in a magnetic tape head. Measurements were made with laser illumination at a wave length of $514 \mathrm{~nm}$. 
chromium photomask SRM. A black-chromi um secondary standard (such as that sold by Roger Sherman Co. [1], Los Gatos, CA) is measured. Note that for measurement of the ferrite core in magnetic tape heads, only Rows $\mathrm{A}$ and $\mathrm{E}$ on the NBS SRM need to be used to generate a calibration curve. The blackchromi um secondary standard is then used to set up and calibrate a reflected (incident) light linewidth measurement system which is used to measure the magnetic tape head parts. The same procedures may be followed for setup and calibration of the reflected light system as was used for the transmitted light measurements.

It is also important that the reflected light system be spectrally filtered for green light. However, the accuracy and reproducibility of this method depends critically on how well the waveforms match at each step. (Note that the coherence parameter and spectral bandwidth are not as critical here as for wafers.) It is recommended that an oscilloscope or chart recorder be used to display and compare the edge image profiles or waveforms at each step to determine how closely they match.

NBS has tested this method, checked the accuracy of the calibration of the black-chromium photomask secondary standard, and compared the reflected light profiles for both the black-chromium photomask and the ferrite gap in the magnetic-tape head samples as shown in figure 2 using the NBS laser linewidth measurement system described in references 2 and 3. Based on this brief study, it appeared that without this two-step process, errors of $0.3 \mu \mathrm{m}$ or more could result. With the two-step process calibration process, these errors could be reduced below $0.1 \mu \mathrm{m}$. In these measurements, the accuracy and reproducibility appear to be limited by the quality (edge sharpness and roughness) of the part being measured as well as by the ability to match waveforms. 
5

References

1. Certain commercial equipment, instruments, or materials are identified in this report in order to adequately specify the experimental procedure. In no case does such identification imply recommendation or endorsement by the National Bureau of Standards, nor does it imply that the material or equipment identified is necessarily the best available for the purpose.

2. Nyyssonen, D., Calibration of Optical Systems for Linewidth Measurements on wafers, Opt. Eng. 21 (5), 882-887 (September-October 1982).

3. Nyyssonen, D., Theory of Optical Edge Detection and Imaging of Thick Layers, J. Opt. Soc. Am. 72, 1425-1436 (1982). 
NBS-114A (REV. 2-8C)

U.S. DEPT. OF COMM.

BIBLIOGRAPHIC DATA

SHEET (See instructions)

1. PUBLICATION OR

REPORT NO.

2. Performing Organ. Report Nof 3. Publication Date

NBSIR $-86 / 3306$

February 1986

4. TITLE AND SUBTITLE

Procedure for Calibration of Ferrite Gaps in Magnetic Tape Heads Traceable to NBS AR-Chromium Optical Linewidth SRMs

5. $A \cup T H O R(S)$

D. NYyssonen

6. PERFORMING ORGANIZATION (If joint or other than NBS, see instructions)

7. Contract/Grant No.

NATIONAL BUREAU OF STANDARDS

DEPARTMENT OF COMMERCE

WASHINGTON, D.C. 20234

8. Type of Report \& Period Covered

9. SPONSOFWNG ORCANIZATION NAME AND COMPLETE ADDRESS (Street, CIty, Stote, ZIF)

10. SUPPLEMENTARY NOTES

Document describes a computer program; SF-185, FIPS Software Summary, is attached.

11. ABSTRACT (A 200-word or less factual summary of most significant information. If document includes a significant bibliography or literature survey, mention it here)

Accurate calibration of micrometer and submicrometer optical linewidth measuring systems requires that the calibration standard match the properties of the line to be measured. I'he NBS photomask linewidth standards have been designed for use by the integrated circuit community and are not directly suitable for use in other applications. A method of calibrating systems for measuring the width of ferrite gaps in magnetic calibrating systems for measuring the width of ferrite gaps in magnetic tape heads has been developed that involves a two-step calibration using the NBS antireflecting-chromium photomask as the primary reference standard. This primary standard is used in transmitted green light to calibrate the linewidths on a secondary black-chromium photomask. This is a valid procedure because these lines are patterned in black-chromi um layers that are thin compared to the wavelength of the green light and have negligible transmission. Since this secondary black-chromium photomask has similar optical properties to ferrite gaps when viewed in reflected green light, it can then be used to calibrate the linewidth measuring system to be used for ferrite gaps. The results of a preliminary study of this method shows that the errors associated with this two-step process are below $0.1 \mu \mathrm{m}$. The study also indicated that without this two-step process, the errors could be $0.3 \mu \mathrm{m}$ or more.

12. KEY WORDS (Six to twelve entries; alphabetical order: copitolize only proper names; and separate key words by semicolons) dimensional metrology; gapwidth; linewidth; NBS photomask standards - magnetic-tape heads; tape-head gaps

\section{AVAILABILITY}

[X] Unlimited

For Official Distribution. Do Not Release to NTIS

$\square$ Order From Superintendent of Documents, U.S. Government Printing Office, Washington, D.C. 20402.

[X] Order From National Technical Information Service (NTIS), Springfield, VA. 2216I
14. NO. OF

PRINTED PAGES

8

15. Price

$$
\$ 9.95
$$



